\title{
Isolation and Characterization of Mycoplasma mycoides Subspecies capri from Milk of Natural Goat Mastitis Cases
}

\author{
Vijay Kumar, ${ }^{1}$ Rajneesh Rana, ${ }^{2}$ Somya Mehra, ${ }^{1}$ and Pramod Kumar Rout ${ }^{1}$ \\ ${ }^{1}$ Central Institute for Research on Goats, Makhdoom, P.O. Farah, Mathura 281122, Uttar Pradesh, India \\ ${ }^{2}$ Division of Bacteriology and Mycology, Indian Veterinary Research Institute, Izatnagar, Bareilly 243 122, Uttar Pradesh, India \\ Correspondence should be addressed to Rajneesh Rana; rajneeshrana01@yahoo.com
}

Received 4 April 2013; Accepted 24 April 2013

Academic Editors: P. Butaye, J. Cabaret, and I. Nsahlai

Copyright ( 2013 Vijay Kumar et al. This is an open access article distributed under the Creative Commons Attribution License, which permits unrestricted use, distribution, and reproduction in any medium, provided the original work is properly cited.

\begin{abstract}
Association of Mycoplasma mycoides subspecies capri $(\mathrm{Mmc})$ with natural goat mastitis has been studied earlier largely by detecting the $M m c$ DNA using molecular methods. However, report on detection of cultivable $M m c$ isolates from natural goat-mastitis milk is still very rare. In this study, $M m c$ was isolated from milk samples $(n=171)$ of goats with or without clinical signs of mastitis. $\mathrm{Mmc}$ isolates were further characterized by biochemical and species-specific PCR methods. Intra species strain variation was also studied by $16 \mathrm{~S}$ amplified rDNA restriction analysis (16S ARDRA). The study recovered a total of $6 \mathrm{Mmc}$ isolates (3.5\%). Three types of intraspecies variants among the recovered $M m c$ isolates were found by $16 \mathrm{~S}$ ARDRA. The study concluded that $M m c$ may be an etiological agent of mycoplasmal mastitis in Indian goat herds.
\end{abstract}

\section{Introduction}

Mycoplasma mycoides subsp. capri $(\mathrm{Mmc})$ belongs to the "Mycoplasma mycoides" cluster (M. capricolum subsp. capricolum, M. capricolum subsp. capripneumoniae, M. mycoides subsp. mycoides large colony type (LC), M. mycoides subsp. mycoides small colony type (SC), Mycoplasma spp. bovine group 7, and $M m c$ ) and is reported to cause a pattern of disease (mastitis, arthritis, keratoconjunctivitis, and pleuropneumonia) in goats, similar to those induced by the rest of the species of the mycoides cluster and other mycoplasmas, namely, M. agalactiae and M. putrefaciens $[1,2]$. Mastitis is one of the manifestations of contagious agalactia (CA) [3] and is characterized by clinical signs like heat, pain, swelling, and redness in the udder besides alteration in milk (clot, flakes, discoloration, and reduction or complete cessation of milk yield). CA is prevalent in several regions of the world [4] by causing high morbidity (26.1-100\%) in adult goats and 36.5 to $100 \%$ in kids [5] along with $25 \%$ and $90 \%$ mortality in adult goats and kids, respectively [6]. In goat-rearing units the economic loss may reach up to $15-20 \%$ [4].

Although M. agalactiae is known as the classical etiological agent of CA and/or mastitis, other species of the mycoides cluster have also been found to be associated with goat mastitis in different countries [7-9]. Very recently, Amores et al. [9] have detected $M m c$ using polymerase chain reaction (PCR) from bulk tank milk which was collected from goats exhibiting clinical signs of mastitis from a CA endemic area. However, there is no report about the isolation of $\mathrm{Mmc}$ from natural goat's mastitis except for the experimental study of Misri et al. [2] and D'Angelo et al. [10].

In view of the dearth of information on the association of $\mathrm{Mmc}$ with goat mastitis on culture bases, the present study was carried out to determine the involvement of $\mathrm{Mmc}$ as well as intraspecific strain variation by isolation, characterization based on species specific PCR and 16S amplified rDNA restriction analysis (16S ARDRA) pattern.

\section{Materials and Methods}

2.1. Classification of Goats for Sampling. Goats exhibiting the clinical signs of mastitis, that is, swollen udder with pain, secreting altered milk, fever, lethargy, and labored breathing, and goats either living in close proximity to goats suffering from mastitis or in herds having a history of CA, were selected 
TABLE 1: Details of primers used in study.

\begin{tabular}{|c|c|c|c|c|c|}
\hline Primer & $\begin{array}{l}\text { Specificity to } \\
\text { species }\end{array}$ & Sequence & $\begin{array}{c}\text { Target } \\
\text { gene/region }\end{array}$ & $\begin{array}{l}\text { Annealing } \\
\text { temperature }\end{array}$ & Reference \\
\hline $\mathrm{P} 4 / \mathrm{P} 6$ & $\begin{array}{r}M m c^{*} \\
\text { PCR }\end{array}$ & $\begin{array}{c}5^{\prime} \text {-ACTGAGCAATTCCTCTT-3' } \\
5^{\prime} \text {-TTAATAAGTCTCTATATGAAT-3' }\end{array}$ & CAP-21 & $46^{\circ} \mathrm{C}, 90 \mathrm{sec}$ & {$[16]$} \\
\hline $\mathrm{P} 4 / \mathrm{P} 5$ & $M m m \mathrm{LC}^{*}$ & $\begin{array}{c}5^{\prime} \text {-ACTGAGCAATTCCTCTT-3' } \\
5^{\prime} \text {-TTAAATAAGTTTGTATATGAAT-3' }\end{array}$ & CAP-21 & $54^{\circ} \mathrm{C}, 30 \mathrm{sec}$ & {$[16]$} \\
\hline Mag-F/Mag-R & M. $a g^{*}$ & $\begin{array}{l}\text { 5'-CCTTTTAGATTGGGATAGCGGATG-3' }^{\prime} \\
5^{\prime} \text {-CCGTCAAGGTAGCGTCATTTCCTAC-3' }\end{array}$ & $16 \mathrm{~S}$ rRNA & $60^{\circ} \mathrm{C}, 60 \mathrm{sec}$ & [17] \\
\hline MputF/MputR & M. put ${ }^{*}$ & $\begin{array}{c}5^{\prime} \text {-AAATTGTTGAAAAATTAGCGCGAC-3' } \\
5^{\prime} \text {-CATATCATCAACTAGATTAATAGTAGCACC-3' }\end{array}$ & $\operatorname{Arc} B$ & $52^{\circ} \mathrm{C}, 15 \mathrm{sec}$ & {$[18]$} \\
\hline MCCPL1-L/MCCPL1-R & $M c c^{*}$ & $\begin{array}{l}5^{\prime} \text {-AGACCCAAATAAGCCATCCA-3' } \\
5^{\prime} \text {-CTTTCACCGCTTGTTGAATG-3' }\end{array}$ & $L p p A$ & $51^{\circ} \mathrm{C}$ & [19] \\
\hline P67BG7-L/P67BG7-R & $\operatorname{Mbg} 7^{*}$ & $\begin{array}{l}5^{\prime} \text {-GGTAATTCGAATAATGATCCT-3' } \\
5^{\prime} \text {-TAAGTTTATTGAATTAAAGCG-3' }\end{array}$ & P67 gene & $46^{\circ} \mathrm{C}$ & {$[20]$} \\
\hline
\end{tabular}

${ }^{*}$ Mmc: M. mycoides subsp. capri, Mmm LC: M. mycoides susp. mycoides large colony type, M. ag: M. agalactiae, Mcc: M. capricolum subsp. capricolum, Mbg7: $M$. bovine group 7.

for sampling. Goats not exhibiting clinical mastitis were taken as asymptomatic ones and suspected for carriers of mycoplasmas.

\subsection{Goat Herd, Sample Collection, and Isolation of Mycoplas-} mas. A total of 171 goats were sampled for milk from five different goat herds of Mathura region (CIRG, Makhdoom; Jhandipur, Chattar Singh Ka Nagla, Keetham and Agra) that facing the problems of CA and/or mastitis. Out of 171 milk samples, 102 were from clinical mastitis and 69 from asymptomatic goats. Milk samples were collected aseptically in sterile vials, that is, before milking affected teats were cleaned with $70 \%$ ethanol and then the first 2-3 streams were discarded.

Isolation of mycoplasmas from milk samples was performed as described by Carmichael et al. [11] with slight modifications. Briefly, milk samples were inoculated into liquid Hank's balanced salt solution (HBSS-L; pH 7.6-7.8) medium and incubated at $37^{\circ} \mathrm{C}$ under $5 \% \mathrm{CO}_{2}$ for up to 14 days and subsequently transferred on solid Hank's balanced salt solution (HBSS-S) medium. The probability of L phase variants was ruled out by forward and reversal passages in the artificial medium.

2.3. Biochemical Characterization. A preliminary characterization of the isolates was performed by digitonin sensitivity and growth inhibition tests as per the method described elsewhere [12] and Giemsa method of staining. This was followed by biochemical tests, namely, glucose fermentation, phosphate reduction, gelatin hydrolysis, and film and spot formation test as described earlier [13].

2.4. Confirmation of Isolates by PCR. Genomic DNA of the isolates was extracted from late exponential growth phase using the phenol-chloroform method described by van Kuppeveled et al. [14], and purity and concentration of DNA was checked on $0.7 \%$ agarose gel and spectrophotometric analysis according to Sambrook et al. [15].
Mycoplasma isolates were confirmed by employing $\mathrm{Mmc}$ specific PCR and the presence of other mycoplasmas was ruled out by conducting the respective species-specific PCRs according to respective protocols described elsewhere as referred in Table 1 . The Qiagen PCR core kit was used to perform all the PCRs and consequent PCR products were checked on $2 \%$ agarose gel.

2.5. Characterization of Intraspecies Strain Variation Using $16 S$ $A R D R A$. The $16 \mathrm{~S}$ rDNA of all isolates was amplified by using the universal primer pair pA $\left(5^{\prime}\right.$-AGAGTTTGATCCTGGCTCAG- $\left.3^{\prime}\right)$ and $\mathrm{pH}\left(5^{\prime}\right.$-AAGGAGGTGATCCAGCCGCA$\left.3^{\prime}\right)$ for 30 cycles $\left(20 \mathrm{sec} .94^{\circ} \mathrm{C}\right.$; $15 \mathrm{sec} .57^{\circ} \mathrm{C}$; and $30 \mathrm{sec}$. $72^{\circ} \mathrm{C}$ ) using Qiagen PCR core kit as per Edwards et al. [21]. The resultant amplicon (1500 bp) was purified by using purification kit (Bangalore Genei, India). It was subsequently digested with restriction enzyme Alu I (Fermentas, sequence: $\mathrm{AG}^{\wedge} \mathrm{CT}$ ) and the restriction fragments were separated on $3 \%$ NuSieve 3:1 agar by using the method of Stakenborg et al. [22].

\section{Results and Discussion}

Out of 171 clinical and asymptomatic samples, a total of 45 samples showed fine turbidity and $\mathrm{pH}$ shift (acidic) imparting a yellow color to the broth medium within 3 to 10 days indicating the mycoplasma growth. After following the protocol of 4-5 reversal and 3-4 forward passages, the possibility of "L phase variant" was ruled out. Only 6 (3.5\%) samples yielded colonies of 1 to $2 \mathrm{~mm}$ size exhibiting typical fried egg appearance on HBSS-S medium. Their growth characteristics were indicative of the mycoplasmas. Of six isolates, 5 were recovered from clinical mastitis milk, whereas one (isolate number 6) was from subclinical mastitis milk. These growth evidences were in accordance with Razin and Freundt [23] and Sori et al. [24]. In the study, the isolation rate $(3.5 \%)$ was found to be in agreement with Ikhloea et al. [25], who obtained similar results of 3.7 to $11 \%$; however, our 


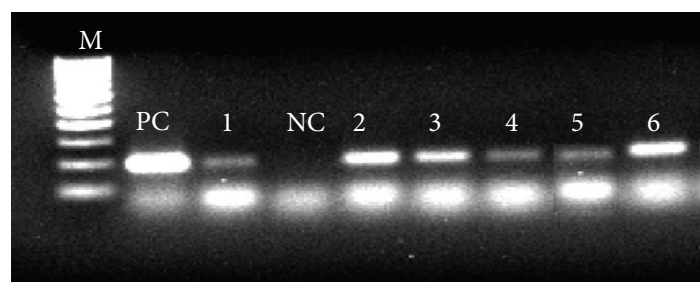

Figure 1: M. mycoides subsp. Capri-specific PCR exhibiting 195 bp amplicon. M: 100 bp DNA ladder; PC: positive control (M. mycoides subsp. capri PG-3); NC: negative control; Lanes 1-6: respective isolates.

isolation rate seems to be quite low in contrast to the 25 to $71 \%$ obtained by Gil et al. [26].

All the isolates showed purplish-pinkish coccobacillary bodies with pleomorphic shape and size upon Giemsa staining. The isolates passed filtration test through $0.45 \mu \mathrm{m}$ filter and found to be sensitive to digitonin. Biochemical tests, namely, glucose fermentation and gelatin hydrolysis tests gave positive results, while, film and spot formation test and phosphatase test were negative for all isolates. The isolates exhibited positive growth inhibition test using anti- $M m c$ PG3 antiserum. On the basis of these results all the isolates were suspected to be of $M m c$.

The PCR amplification in Mmc-specific PCR was found positive in all isolates by yielding 195 bp amplicon (Figure 1) the specificity of this PCR was for CAP-21 genomic region [16]. However, none of the species-specific PCR (mentioned in Table 1) except Mmc PCR was amplified against any isolate. Thus the presence of any other species (M. putrefaciens, $M$. agalactiae, $M$. capricolum subsp. capricolum, $M m m$ LC, and $M$. bovine group 7) was ruled out, although they are also known to be associated with goat mastitis milk.

$\mathrm{Mmc}$ isolates were further studied for any intraspecific strain variation using $16 \mathrm{~S}$ ARDRA. The $16 \mathrm{~S}$ rDNA upon digestion with $A l u$ I exhibited strain variation in $M m c$ isolates by revealing three types of ARDRA patterns (Figure 2). The isolate numbers $1,2,3$, and 4 showed a similar band pattern as that of Mmc PG-3 by yielding 5 bands $(236,186,147,105$, and $85 \mathrm{bp}$ ), while isolate numbers 5 and 6 showed different and unique band patterns by yielding $3(620,473$, and $413 \mathrm{bp})$ and 7 (620, 473, 413, 236, 186, 147, and $105 \mathrm{bp}$ ) bands, respectively, which were different than the standard strain PG-3. The similarity in band pattern with that of standard strain PG3 was in agreement with the observations of Stakenborg et al. [22], who observed the same pattern for PG-3 using the same primer and restriction enzyme. However, the different band pattern observed in isolates numbers 5 and 6 was not in agreement with their observation. Our results, that is, different band patterns within species are supported by Monnerat et al. [19] who also found intraspecific strain variation in $l p p A$ gene of $M m c$ strains by using Alu I enzyme. The band pattern different from the reference strain (PG-3) observed by us may be attributed to the presence of different Alu I cutting sites in both of the operons ( $r r n A$ and $r r n B$ ) as described by Bascunana et al. [27].

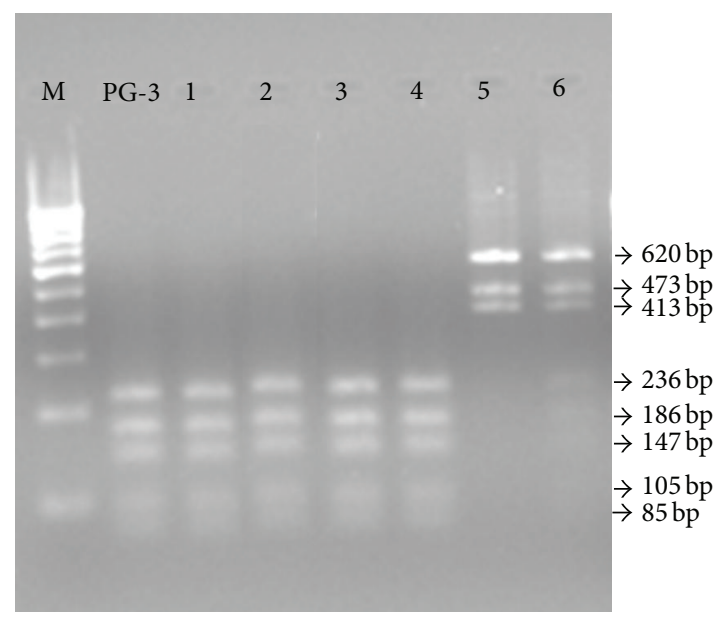

FIGURE 2: Intra specific strain variation in 16S ARDRA profile among $M m c$ isolates. M: 100 bp DNA ladder; PG-3: M. mycoides subsp. capri PG-3; Lanes 1-6: respective isolates. The band, that is, $236 \mathrm{bp}, 186 \mathrm{bp}, 147 \mathrm{bp}$, and $105 \mathrm{bp}$ are visible very faintly in lane number 6 .

Although $M$. agalactiae is known as the main causative agent of mastitis [28] along with other species reported earlier, in our case $M m c$ was isolated from goats having clinical mastitis as well as from asymptomatic goats. The isolation of $M m c$ in the present study has also been supported by the detection of $M m c$ from milk collected from clinical mastitis cases in CA endemic area in Spain [9]. Our findings are experimentally supported by Misri et al. [2], who observed the involvement of $M m c$ in development of goat mastitis after following the Koch's postulate. But the present findings are contradictory to earlier reports describing the association of goat mastitis with other mycoplasma species like $M$. capricolum subsp. capricolum, M. putrefaciens, $M$. arginini and $M m m$ LC $[6,28-31]$. Since the present study does not cover a wide geographic area, therefore an isolation work needs to be carried out at a wider level.

In conclusion, our finding reports the isolation of $\mathrm{Mmc}$ having intra specific strain variation (in $16 \mathrm{~S}$ rDNA) from natural mastitis in goats which have not been reported ever and consequently indicates the association and dually favors the earlier report of development of mastitis in goats after the experimental infection of $M m c$. Also, it reports that, in India, the occurrence of mycoplasmal mastitis in goats may be due to $M m c$ infections as no other mycoplasmal species could be isolated from goat mastitis.

\section{Conflict of Interests}

The authors have no conflict interest to declare.

\section{Acknowledgment}

The authors are thankful to Dr. R. A. J. Nicholas, Mycoplasma Group, Veterinary Laboratories Agency (Weybridge), New Haw, Addlestone, Surrey, UK, for providing reference strains 
of members of mycoides cluster and their monospecific antisera.

\section{References}

[1] G. S. Cottew, A. Breard, A. J. DaMassa et al., "Taxonomy of the Mycoplasma mycoides cluster," Israel Journal of Medical Sciences, vol. 23, no. 6, pp. 632-635, 1987.

[2] J. Misri, P. P. Gupta, and N. Sood, "Experimental Mycoplasma capri mastitis in goats," Australian Veterinary Journal, vol. 65, no. 1, pp. 33-35, 1988.

[3] R. A. J. Nicholas, "Improvements in the diagnosis and control of diseases of small ruminants caused by mycoplasmas," Small Ruminant Research, vol. 45, no. 2, pp. 145-149, 2002.

[4] A. Medanet, D. Zendulkova, and Z. Pospisil, "Contagious agalactia of sheep and goats: a review," Acta Veterinaria Brno, vol. 70, pp. 403-412, 2001.

[5] E. O. De Azevedo, M. D. B. De Alcântara, E. R. Do Nascimento et al., "Contagious agalactia by Mycoplasma agalactiae in small ruminants in Brazil: first report," Brazilian Journal of Microbiology, vol. 37, pp. 576-581, 2006.

[6] K. Saris, "Contagious agalactia," in Mycoplasmas of Ruminants: Pathogenicity, Diagnostics, Epidemiology and Molecular Genetics COST 826 Agriculture and Biotechnology, J. Frey and K. Sarris, Eds., pp. 12-15, Luxembourg, 1996.

[7] H. L. Ruhnke, S. Rosendal, J. Goltz, and T. E. Blackwell, "Isolation of Mycoplasma mycoides subspecies mycoides from polyarthritis and mastitis of goats in Canada," The Canadian Veterinary Journal, vol. 24, pp. 54-56, 1983.

[8] A. J. DaMassa, P. S. Wakenell, and D. L. Brooks, "Mycoplasmas of goats and sheep," Journal of Veterinary Diagnostic Investigation, vol. 4, no. 1, pp. 101-113, 1992.

[9] J. Amores, A. Sánchez, A. Gómez-Martín, J. C. Corrales, A. Contreras, and C. de la Fe, "Surveillance of Mycoplasma agalactiae and Mycoplasma mycoides subsp. capri in dairy goat herds," Small Ruminant Research, vol. 102, pp. 89-93, 2012.

[10] A. R. D’Angelo, A. di Provvido, G. di Francesco et al., "Experimental infection of goats with an unusual strain of Mycoplasma mycoides subsp. Capri isolated in Jordan: comparison of different diagnostic methods," Veterinaria Italiana, vol. 46, no. 2, pp. 199-207, 2010.

[11] L. E. Carmichael, T. D. St George, N. D. Sullivan, and N. Horsfall, "Isolation, propagation, and characterization studies of an ovine Mycoplasma responsible for proliferative interstitial pneumonia," The Cornell Veterinarian, vol. 62, no. 4, pp. 654679, 1972.

[12] W. A. Clyde, "Mycoplasma spp. Identification based upon growth inhibition by specific antisera," Journal of Immunology, vol. 92, no. 6, pp. 958-965, 1964.

[13] H. Ernǿ and L. Stipkovits, "Bovine Mycoplasmas: cultural and biochemical studies," Acta Veterinaria Scandinavica, vol. 14, pp. 436-449, 1973.

[14] F. J. M. Van Kuppeveld, J. T. M. Van der Logt, A. F. Angulo et al., "Genus- and species-specific identification of mycoplasmas by 16S rRNA amplification," Applied and Environmental Microbiology, vol. 58, no. 8, pp. 2606-2615, 1992.

[15] J. Sambrook, E. F. Fritsch, and T. Maniatis, Molecular Cloning Laboratory Manual, Cold Spring Harbor, New York, NY, USA, 1989.
[16] H. Hotzel, K. Sachse, and H. Pfützner, "A PCR scheme for differentiation of organisms belonging to the Mycoplasma mycoides cluster," Veterinary Microbiology, vol. 49, no. 1-2, pp. 31-43, 1996.

[17] Y. R. Chávez González, C. R. Bascuñana, G. Bölske, J. G. Mattsson, C. F. Molina, and K. E. Johansson, "In vitro amplification of the 16S rRNA genes from Mycoplasma bovis and Mycoplasma agalactiae by PCR," Veterinary Microbiology, vol. 47, no. 1-2, pp. 183-190, 1995.

[18] A. Peyraud, S. Woubit, J. B. Poveda, C. De La Fe, P. Mercier, and F. Thiaucourt, "A specific PCR for the detection of Mycoplasma putrefaciens, one of the agents of the contagious agalactia syndrome of goats," Molecular and Cellular Probes, vol. 17, no. 6, pp. 289-294, 2003.

[19] M. P. Monnerat, F. Thiaucourt, J. B. Poveda, J. Nicolet, and J. Frey, "Genetic and serological analysis of lipoprotein LppA in Mycoplasma mycoides subsp. mycoides LC and Mycoplasma mycoides subsp, capri," Clinical and Diagnostic Laboratory Immunology, vol. 6, no. 2, pp. 224-230, 1999.

[20] J. Frey, X. Cheng, M. P. Monnerat et al., "Genetic and serological analysis of the immunogenic $67-\mathrm{kDa}$ lipoprotein of Mycoplasma sp. Bovine group 7," Research in Microbiology, vol. 149, no. 1, pp. 55-64, 1998.

[21] U. Edwars, T. Rogall, H. Blocker, M. Emde, and E. C. Bottger, "Isolation and direct complete nucleotide determination of entire genes. Characterization of a gene coding for $16 \mathrm{~S}$ ribosomal RNA," Nucleic Acids Research, vol. 17, no. 19, pp. 7843-7853, 1989.

[22] T. Stakenborg, J. Vicca, R. Verhelst et al., "Evaluation of tRNA gene PCR for identification of mollicutes," Journal of Clinical Microbiology, vol. 43, no. 9, pp. 4558-4566, 2005.

[23] S. Razin and E. A. Freundt, "The Mollicutes, Mycoplasmatales, and Mycoplasmatacae," in Bergey's Manual of Systematic Bacteriology, N. R. Krieg and J. G. Holt, Eds., vol. 1, pp. 740-742, The Williams \& Wilkins, Baltimore, Md, USA, 1984.

[24] T. D. V. M. Sori, A. D. V. M. Zeleke, E. D. V. M. Gelaye, and F. D. V. M. Regassa, "Isolation and identification of Mycoplasma mycoides subsp. mycoides small colony type in Eastern Ethiopia," International Journal of Applied Research in Veterinary Medicine, vol. 3, no. 1, pp. 30-34, 2005.

[25] J. O. Ikheloa, A. T. P. Ajuwape, and A. I. Adetosoye, "Biochemical characterization and serological identification of mycoplasmas isolated from pneumonic lungs of goats slaughtered in abattoirs in Northern Nigeria," Small Ruminant Research, vol. 52, no. 1-2, pp. 93-97, 2004.

[26] M. C. Gil, M. De Hermoso Mendoza, J. Rey, J. M. Alonso, J. B. Poveda, and J. De Hermoso Mendoza, "Aetiology of caprine contagious agalactia syndrome in Extremadura, Spain," Veterinary Record, vol. 144, no. 1, pp. 24-25, 1999.

[27] C. R. Bascunana, J. G. Mattsson, G. Bolske, and K. E. Johansson, "Characterization of the 16S rRNA genes from Mycoplasma sp. strain F38 and development of an identification system based on PCR," Journal of Bacteriology, vol. 176, no. 9, pp. 2577-2586, 1994.

[28] D. Bergonier, X. Berthelot, and F. Poumarat, "Contagious agalactia of small ruminants: current knowledge concerning epidemiology, diagnosis and control," OIE Revue Scientifique et Technique, vol. 16, no. 3, pp. 848-873, 1997.

[29] Bar-Moshe, E. Rapport, E. Bogin, and E. Lebel, "Vaccination trial against caprine. Mycoplasma mycoids subsp.mycoids (LC type) infection in goats, infectivity trials, vaccination and challenge," Refuah Veterinarith, vol. 39, pp. 77-88, 1982. 
[30] A. J. DaMassa, D. L. Brooks, C. A. Holmberg, and A. I. Moe, "Caprine mycoplasmosis: an outbreak of mastitis and arthritis requiring the destruction of 700 goats," Veterinary Record, vol. 120, no. 17, pp. 409-413, 1987.

[31] P. Kumar, A. Roy, B. B. Bhanderi, and B. C. Pal, "Isolation, 'identification and molecular characterization of Mycoplasma isolates from goats of Gujarat State, India," Veterinarski Arhiv, vol. 81, no. 4, pp. 443-458, 2011. 

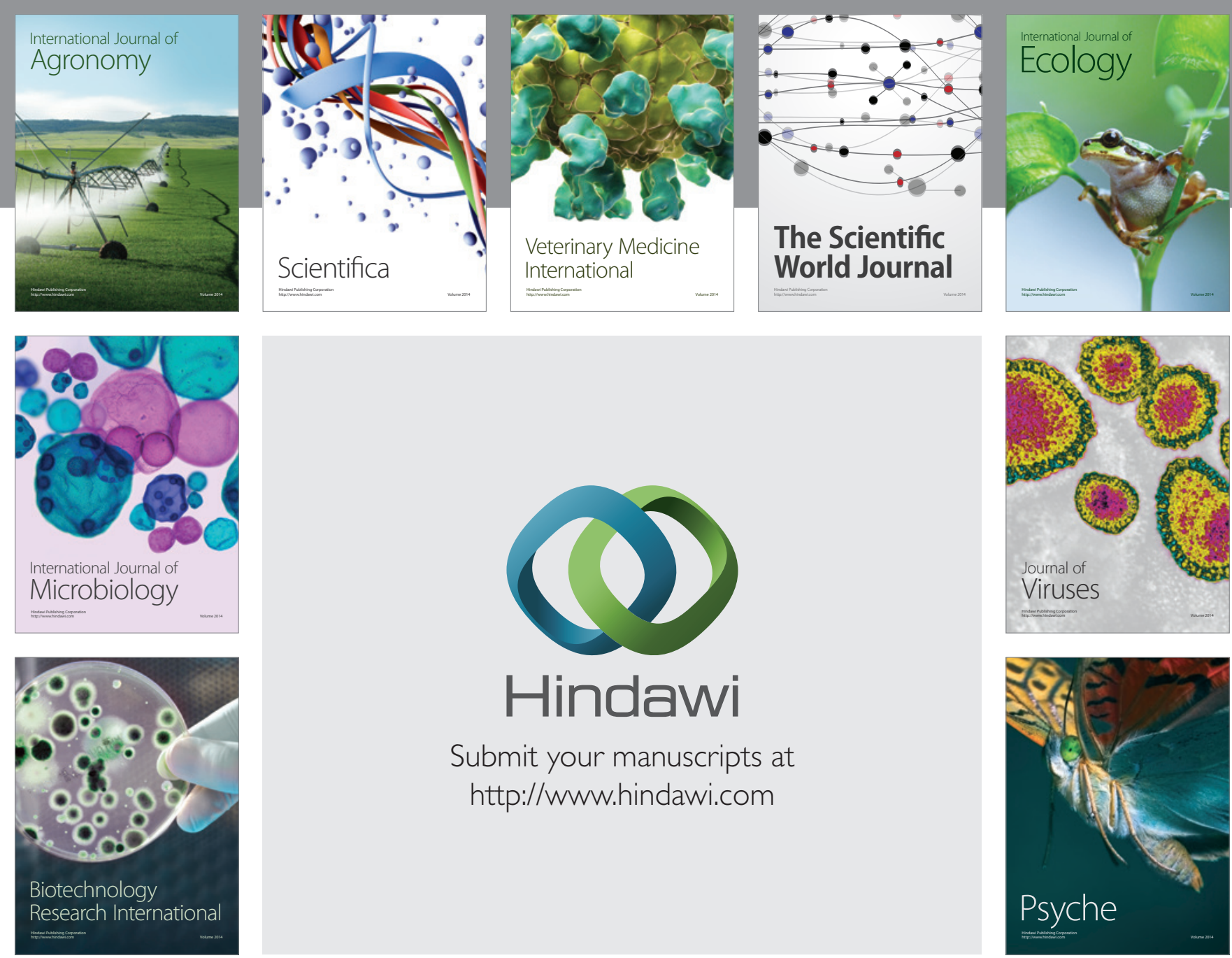

Submit your manuscripts at http://www.hindawi.com
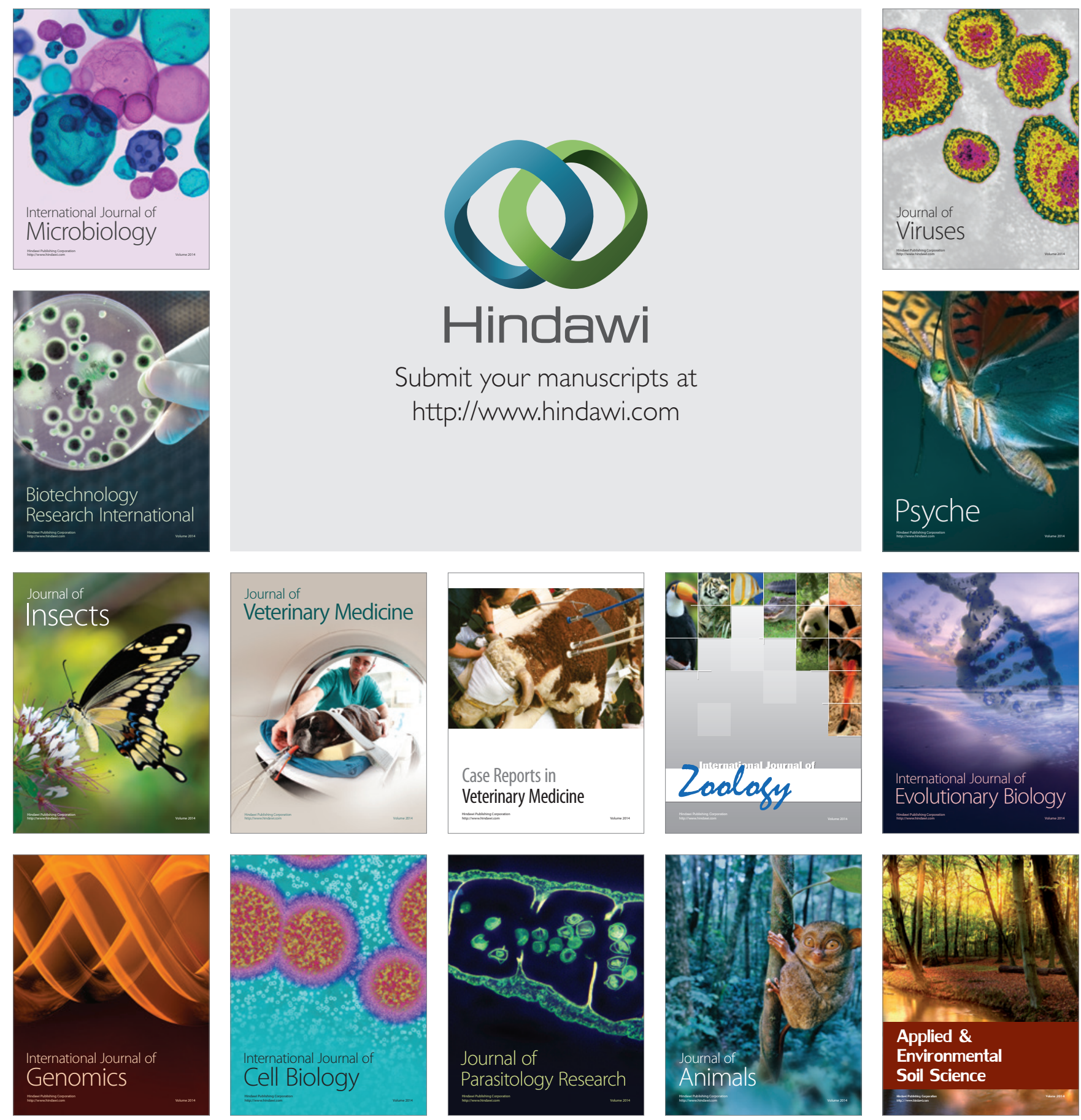